Ancuța SMĂDU

Şcoala doctorală de ştiințe socio-umane

Universitatea „Dunărea de Jos" din Galați

\title{
„VÂRSTELE” LITERATURII POSTBELICE IDENTIFICATE ÎN OPERA GABRIELEI ADAMEȘTEANU
}

Originară din București, Gabriela Adameșteanu debutează ca profesoară de lucru manual și gospodărie. După 18 de ani, absolvă Liceul Nr.2 din Pitești și devine studentă a Facultății de Limba și Literatura română a Universității din București. La terminarea facultății primește un post în redacția de dicționare enciclopedice din cadrul Editurii Poilitice. Debutează în anul 1971 cu povestirea Prietenie în revista Luceafărul și, la scurt timp, publică proză în România literară.

Primul său roman, Drumul egal al fiecărei zile, publicat în anul 1975, se bucură de o bună primire, autoarea fiind premiată de Uniunea Scriitorilor și de Academia Română. Publică mai apoi un volum de proză scurtă, apoi încă un roman Dimineața pierdută, care o situiază pe autoare în prim-planul vieții literare. O dată cu Revoluția din 1989, Gabriela Adameșteanu devine redactor-șef adjunct al Revistei 22, transformându-se treptat într-o energică organizatoare, dar si într-o publicistă care critică de pe o poziție intransigentă „comunismul rezidual” din România.

Autoarea a început să publice după anii 1970, proza acesteia fiind recunoscută de modul în care reflectă realitatea. Ce se observă cu ușurință la autoare este realitatea devenită foarte poroasă și anume o realitate mărunțită, care oscilează în interiorul căreia apar personaje „inconsitente”.

Literatura românească postbelică suferă de prezența literatorului, ceea ce conduce la o coordonată subversivă și funcționează ca o opoziție față de regimul totalitar. Din aceste motive, numeroase opere nu au putut beneficia de o receptare corectă dupa anii 90 .

Dificultatea de încadrare a operelor Gabrielei Adameșteanu într-o generație anume, cât și ilustrarea elementelor originale într-un peisaj literar postbelic se explică prin intermediul scrierii sale, prin poetica ei nemărturisită de a reuși să îmbine elementele clasice cu cele moderne.

În Istoriile literare, autoarea beneficiază de o imagine concretă, oferită în mare parte de romanulul care a consacrat-o Dimineață pierdută, publicat în 1984. Astfel că recitit după mai bine de trei decenii de la apariție, acest 
roman reprezintă una dintre cele mai importante realizări ale genului reprezentat în perioada comunistă şi postcomunistă.

Monica Lovinescu afirma în anul apariției romanului că acesta este

„un roman generos cu cititorul: îl implică direct, lăsându-l în pricipiu să-și aleagă perspectiva din care-l va citi- după cum o va prefera pe aceea a unui personaj sau a altuia, dar nu-l derutează nici o clipă, viziunea de ansamblu nefiind în fond relativizată, ci adăugită, completată de versiunile diferiților protagonişti. De la primele pagini, de la primele rânduri, știi, simți că povestirea personajelor devine a ta, că nu vei mai ieși din ea până în final şi că de-abia după o astfel de lectură, mereu participativă, își vei oferi luxul de a remarca și analiza prin ce procedee ți s-a pregătit o astfel de capcana".

Romanul apare ca fiind reprezentarea mai multor epoci ce corespund perioadelor de timp evocate anterior, la care se adaugă și vremurile de astăzi, pentru că această scriere amplă prezintă un anume sens al istoriei care nu își poate pierde valabilitatea, indiferent de tipul de societate ce carcaterizează la un moment dat o națiune. Celelalte scrieri sunt considerate a fi fie "parazitare", fie lipsite de interes prin ele însele, sau mai rău decât atât, ",ratate”.

Definit de către Nicolae Manolesu „roman al crizei de adolescență”, Drumul egal al fiecărei zile este totuși o carte scrisă bine, cu nerv și presărate cu ironie. Chiar dacă nu întâlnim un ton melancolic sau duios-nostalgic al jurnalelor intime și nici excesul de lirism, care se regăsește adesea în proza tinerelor autoare, acest roman poate fi în parte autobiografic, relatarea făcându-se la persoana I. Intelingență artistică este ceea ce denotă acest roman fiindcă presupune o analiză rece, cvasi crudă, o obiectivitate „medicală”, fără a fi poetizat, romanul nu este nici sumbru, nici amar, ci pur și simplu exact și meticulos în observație.

În romanul Drumul egal al fiecărei zile se identifică maniera proprie a autoarei care zugrăvește cu maximă precizie viața cotidiană a românilor la sfârsitul anilor '50 și începutul anilor ' 60 , „,cu privațiunile materiale, cu teama permanentă, dar și de lipsa de perspective", autoarea nu dorește să scoată în evidență într-un mod explicit vechiul regim sau, mai multe decât atât, să culpabilizeze pe cineva.

Autenticitatea și caracterul veridic sunt date și de existența orașului București prezentat în acest roman ca fiind un loc viu cu o viața secretă, născută tot din impulsul acelei rezistențe pe care autoarea dorește să o evidențieze împotriva urâtului, a lipsei de sens, a monotoniei și a cenuşiului existențial pe care o manifestă multe dintre personajele creionate de Gabriela Adameșteanu. De-a lungul romanului, orașul capătă două vârste, devine Bucureștiul din trecut și din prezent. 
Dimineaţă pierdută este „un cumul de romane” centrate fiecare pe câte un protagonist cu funcție iradiantă în narațiune. Astfel că ritmul al fi cel al Vicăi Delcă, un personaj unic în literatura română, înzestrat cu numeroase valențe expresive din punct de vedere al comportamentului și al limbajului, ce este contruit după o partitură ingenioasă. Protagonistei îi este atribuit rolul de raisonneur al unor medii sociale diametral opuse celui din care ea face parte, ceea ce demostrază specificiul observațiilor sale, care au un anumit grad de spectaculozitate.

Marian Popa consideră că toate cărțile Gabrielei Adameșteanu sunt supraapreciate de critica de întâmpinare, de aceea punctul său de vedere este încă de la început extrem de dur considerând că volumul de debut nu este nimic altceva decât "o acumulare impresionantă de evenimente minore și de detalii ale cotidianului cu determinări în anii 50 constituite în burți epice". Cu aceeași duritate și neîndreptățire judecă și romanul din 1984, înțelegând simbolul „dimineții pierdute " ca nefiind relevant, indiferent de contextul în care acesta ar putea fi aplicat.

Nicolae Manolescu afirma că în proza generației ‘60,

„realitatea a rămas mai mereu în cadre tradiționale, privită de sus global, prin intermediul unor personaje coerente psihologic, indiferent dacă romaul era istoric, obiectiv sau analitic. Scriitorii care au început să publice după anii 1970 au invocat în primul rând în felul de a considera realitatea. Metaforic, perspectiva lor poate fi numită mioapă. Noii prozatori preferă aspectul istoric al realității pe acela cotidian și, lucru foarte important, făceau nesigură, dacă nu imposibilă, ierarhizarea evenimentelor în funcție de semnificația lor. Aplicare și interes pentru toate scrierile autoarei până la acel moment dovedise și criticul Eugen Siomion, care era de părere că miza lecturii acelor scrieri consta în demonstrarea reuşitei autoarei Gabriela Adameșteanu de a schimba ceva, şi anume "tipologia feminității din proza românească".

Criticul învocă o anumite cruzime realistă care face ca mărcile tradiționale ale literaturii feminine, "gustul pentru melodramă", "lirismul”, "senzualitatea”, „psihologismul fin”să lipsească aproape total. Astfel, criticul prezintă o viziune prismatică asupra unei lumi dominate de medioccrități, vulgarități, și duplicități, impunând acea observatoare rea, neînduplecată a „imperfecțiunilor umane”.

Și Monica Lovinescu este o voce care fixase în anul apariției romanului celui mai des invocat câteva repere interpretative, raportându-se la binomul tradițional-modern, considerând romanul Dimineată pierdută ca fiind unul cu adevărat modern. De asemenea, sunt prezente tehnici întrebuințate, dar mai cu seamă, sunt prezente oscilații ale monologului interior cu dialogul care sunt "atât de bine stapânite, ținute în frâu, 
justificate, chemate de structura romanului și de cerințele personajelor, încât devin invizibile".

Dimineată pierdută este și un tulburător roman al vârstelor, al trecerii timpului neidentificându-se nimic strident, ostentativ, în trecerea de la un nivel al duratei la altul. În roman totul decurge firesc, totul pare firesc în ceea ce numește chiar autoarea un spectacol imposibil în care ireversibilul devine reversibil, iar ceea ce nu s-a întâmplat încă este cunoscut deja ca un fapt consumat. În articolul $O$ dimineață de o sută de ani, Valeriu Crisrea observă că

„emoția pe care autoarea o emană în roman este neobisnuită și că modul în care este percepită viața este învăluit într-o aură de melancolie, timpul curge când într-o direcție, când în alta, uneori întorcându-și nefiresc cursul, alteori, înspre izvoare".

Raportându-ne la perspectiva narativă care se schimbă odată cu fiecare dintre personajele cărora li se dă cuvântul în deplină libertate, fără cenzură auctorială, caleidoscopul acesta mișcător se adună în final într-o perspectivă atât de unitară, acest roman poate fi citit dintr-o singură respirație, ca un roman tradițional, și numai după aceea poți să realizezi prin intermediul căror strategii narative a fost obținută cugetarea, care este construită într-o manieră „,atât de savantă”.

Scrisul Gabrieiel Adameșteanu prezintă forță şi rafinament în proporții egale. Forța derivă din caracterul lumilor pe care le restituie plenar și subtil, astfel că romanele sale cuprind elemente specifice cronicilor de familie care au capacitatea de a păstra în ele însele istoria socială trăită, suportată de protagoniști, istoria având capacitatea de a decoda caractere și atitudini. Sensul istoriei, deja amintit, decurge din acaeastă dimeniune participativă a romanului ce nu are legătură doar cu ideea de lectură, ci și $\mathrm{cu}$ aceea de consubstanțialitate între sensul profund, general și experiența vie, "carnală" a personajelor.

Dintre toate romanele publicate de către Gabriela Adameșteanu reiese o viziune modernă asupra unei lumi particulare, o viziune originală și cuprinzătoare, formată din numeroase edificii, tot atâtea câte corpuri de operă există. Cadrele realității se modifică în funcție de un sens profund al istoriei și al vieții surprinse într-o desfăşurare atipică în care fiecare scenă este provizorie în raport cu ceea ce urmează, dar și cu lumea celei care deja s-a consumat. De aceea, lumea operei Gabrielei Adameșteanu este cea în care trecutul e mai surprinzător decât viitorul fiindcă nu există o certitudine a faptul că aceste romane vor fi recitite de către pasionați. 


\section{BIBLIOGRAFIE:}

Antofi, Simona, GENERAL DICTIONARY OF ROMANIAN LITERATURE OBVERSE AND REVERSE CRITICAL RECEPTION, în Oana Cenac (coord., edit.), International Conference of Common Vocabulary/Specialized Vocabulary: Manifestations of Creativity of Human Language, 6-7 iunie 2014, publicate în volumul MANIFESTARI ALE CREATIVITATII LIMBAJULUI UMAN, 2014, p. 13-19, Accession Number WOS:000378446400001.

Antofi, Simona, Contemporary Critical Approaches to the Romanian Political and Cultural Ideology of the XIXth Century - Adrian Marino, Al treilea discurs. Cultura, ideologie si politica in Romania / The Third Discourse. Culture, Ideology and Politics in Romania, în Antofi, S., Ioana N., Necula, G., Ifrim, N., Crihană, A., (edit.), Procedia Social and Behavioral Sciences, 4th International Conference on Paradigms of the Ideological Discourse - The Dynamics of Terminologies and (Re)Shaping of Ideologies, 2012, p. 22-28, DOI: 10.1016/j.sbspro.2012.10.005, Galati, ROMANIA, 31 mai - 1 iunie 2012, Accession Number WOS:000361477200004

Cenac, Oana, Discurs ideologic în "Ateneu" 1965, Actele conferinței internaționale Lexic comun / Lexic specializat. Democratizarea cunoașterii" sau migrația lexicului specializat spre lexicul comun, ediția a X-a, Universitatea „Dunărea de Jos" din Galați, Facultatea de Litere, Centrul de Cercetare Comunicare interculturală și literatură, 19 - 20 mai 2017, publicată în Analele Universității „Dunărea de Jos” din Galați, Fascicula XXIV Lexic comun / lexic specializat, revistă indexată in bazele de date internaționale EBSCO: https://www.ebscohost.com/titleLists/cms-coverage.pdf, MLA (Modern Language Association, New York, www.mla.org) - MLA International Bibliography $\mathcal{E}$ Directory of Periodicals, CEEOL și Fabula. La recherche en littérature (www.fabula.org), anul X, nr. 2(18) /2017, Editura Casa Cărții de Ştiință, Cluj-Napoca, 2017, ISSN 1844-9476, p. 31-48.

Cenac, Oana, (2014). Aspects of Popular Stylistic Language in the Work of Ion Creangă in Proceedings of the International Conference of Common Vocabulary/Specialized Vocabulary: Manifestations of Creativity of Human Language, 6-7 of June, 2014, p. 178 - 186, WOS: 000378446400018, citat în Nicoleta Hristu Hurmuzache, IDENTITATEA MALADIVĂ ÎN ROMANUL LUI MAX BLECHER, în volumul Spații culturale deschise. Latinitate și romanitate, Casa cărții de știință, Cluj-Napoca, 2016, ISBN 978-606-17-10812, WOS: 000378446400018

Călinescu, Matei, A citi, a reciti. Către o poetică a (re)lecturii, Iași, Editura Polirom, Iaşi, 2000.

Cristea, Valeriu, O dimineață de o sută de ani, „,România literară”, 6 septembrie 1984. Ifrim, Nicoleta, Theoretical Aspects of Identity Discourse in Post-totalitarian Cultures, Conferința Internațională Paradigma discursului ideologic (PID 4), 31 mai1 iunie 2012, Facultatea de Litere, Galați, în Procedia-Social and Behavioral 
Journal (ISSN: 1877-0428) (ISSN: 1877-0509), vol.63/2012 ELSEVIER (www.elsevier.com) indexată ScienceDirect, Scopus, Thomson Reuters Conference Proceedings Citation Index (ISI Web of Science), pp.35-40, DOI 10.1016/j.sbspro.2012.10.007, http://www.sciencedirect.com/science/journal/18770428/63/supp/C, WOS:000361477200006 (indexare ISI)

Ifrim, Nicoleta, History and Identity in Post-Totalitarian Memoir Writing in Romanian, CLCWeb: Comparative Literature and Culture (ISSN 1481-4374) http://docs.lib.purdue.edu/clcweb/, nr. 16.1 / March 2014, Purdue University Press, revistă indexată ISI Art and Humanities Citation Index http://docs.lib.purdue.edu/clcweb/vol16/iss1/11/, Accession Number WOS:000333326200011.

Lovinescu, Monica, Dimineaț̆a perdută sau România pierdută, la Europa Liberă, 14 septembrie 1984.

Manolescu, Nicolae, Adameșteanu Gabriela \& Novac Constantin, Tineri romancieri in România literară, 6 noiembrie 1975.

Popa, Marian, Istoria literaturii române de azi pe mâine, vol II, 23 august 1994-22 decembrie 1989, versiune revizuită și augmentată, Semne, București, 2009, p. 787.

Răsuceanu, Andreea, Portretul orașului la tinerețe. Drumul egal al fiecărei zile, Revista "Steaua", 2015.

Simion, Eugen, Scriitori români de azi, vol IV, Cartea Românească, București, 1989, p.465.

Urian, Tudorel, Arta supraviețuirii, în „România literară”, 12 septembrie 2008.

\title{
The "Ages" of Post-War Literature Identified in Gabriela Adameşteanu's Literary Work
}

\begin{abstract}
The purpose of this article is to bring the author into a literary genre, her works being the subject of histories, as well as studies related to postwar Romanian prose. Numerous literary critics of the time tried to put Gabriela Adamesteanu's prose in a certain period. Taking into account the moment the author started, it could be part of the generation of the seventies writers, but there are different peculiarities in the poetry of her literature that hinder this endeavour. Both the difficulty of framing the work of the author in a particular generation and the specific elements that offer originality can be explained by her writing, through her unmistakable poetics to accommodate two seemingly opposite principles, namely the classic and the modern.
\end{abstract}

Key words: poetics, history, criticism, feminine literature, perspective, feminine imaginary, post-war literature. 